\title{
An EEG Investigation of Sleep Homeostasis in Healthy and CLN5 Batten Disease Affected Sheep
}

\author{
DNicholas Perentos, ${ }^{1}$ (D) Amadeu Q. Martins, ${ }^{1}{ }^{-}$Robin J. M. Cumming, ${ }^{1}$ Nadia L. Mitchell, ${ }^{2}$ David N. Palmer, ${ }^{2}$ \\ Stephen J. Sawiak, ${ }^{3}$ and ${ }^{\circledR}$ A. Jennifer Morton ${ }^{1}$ \\ ${ }^{1}$ Department of Physiology Development and Neuroscience, University of Cambridge, Cambridge CB2 3DY, United Kingdom, ${ }^{2}$ Department of Molecular \\ Biosciences, Faculty of Agricultural and Life Sciences, Lincoln University, Lincoln 7647, New Zealand, and ${ }^{3}$ Behavioral and Clinical Neuroscience Institute, \\ University of Cambridge, Cambridge CB2 3EB, United Kingdom
}

Sheep have large brains with human-like anatomy, making them a useful species for studying brain function. Sleep homeostasis has not been studied in sheep. Here, we establish correlates of sleep homeostasis in sheep through a sleep deprivation experiment. We then use these correlates to elucidate the nature of sleep deficits in a naturally occurring ovine model of neuronal ceroid lipofuscinosis (NCL, Batten disease) caused by a mutation in CLN5. In humans, mutations in this gene lead to cortical atrophy and blindness, as well as sleep abnormalities. We recorded electroencephalograms (EEGs) from unaffected and early stage CLN5 ${ }^{-1-}$ (homozygous, affected) sheep over 3 consecutive days, the second day being the sleep deprivation day. In unaffected sheep, sleep deprivation led to increased EEG delta $(0.5-4 \mathrm{~Hz})$ power during non-rapid eye movement (NREM) sleep, increased time spent in the NREM sleep state, and increased NREM sleep bout length. CLN5 ${ }^{-1-}$ sheep showed comparable increases in time spent in NREM sleep and NREM sleep bout duration, verifying the presence of increased sleep pressure in both groups. Importantly, $\mathrm{CLN}^{-1-}$ sheep did not show the increase in NREM sleep delta power seen in unaffected sheep. This divergent delta power response is consistent with the known cortical degeneration in CLN5 ${ }^{-1-}$ sheep. We conclude that, whereas sleep homeostasis is present in CLN5 ${ }^{-1-}$ sheep, underlying CLN5 ${ }^{-1-}$ disease processes prevent its full expression, even at early stages. Such deficits may contribute to early abnormalities seen in sheep and patients and warrant further study.

Key words: EEG; neuronal ceroid lipofuscinosis; sheep; sleep deprivation; sleep homeostasis; thalamus

Significance Statement

Sleep abnormalities pervade most neurological diseases, including the neuronal ceroid lipofuscinoses (NCLs). Here, we show that, in an ovine model of a variant late-infantile NCL, there is abnormal expression of sleep homeostasis. Whereas some sleep pressure correlates respond to sleep deprivation, the strongest electroencephalogram (EEG) correlate of sleep pressure, non-REM delta power, failed to increase. This highlights the relevance of sleep deficits in this disease, in which the drive for sleep exists but the underlying disease prevents its full expression. Sleep abnormalities could contribute to early disease symptoms such as behavioral disorder and cognitive decline. Our study also shows sleep homeostatic EEG correlates in sheep, opening up new opportunities for studying sleep in a large social mammal with complex human-like brain neuroanatomy.

\section{Introduction}

Although the overall function of sleep is still debated, its value for healthy neurological and cognitive function is undeniable (McCoy and Strecker, 2011; Xie et al., 2013). Sleep deficits

\footnotetext{
Received Nov. 30, 2015; revised May 30, 2016; accepted June 7, 2016.

Author contributions: N.P. and A.J.M. designed research; N.P. and A.Q.M. performed research; N.L.M. and D.N.P. contributed unpublished reagents/analytic tools; N.P., A.Q.M., R.C., A.J.M., and S.J.S. analyzed data; N.P., A.Q.M., R.C., A.J.M., N.L.M., and D.N.P. wrote the paper.

This work was funded by CHDI, Inc. (A.J.M.). Founding the sheep flock and costs in New Zealand relating to the rearing and genotyping of the animals were funded by a series of grants from the Neurological Foundation of New Zealand and the Batten Disease Support and Research Association (D.N.P. and N.L.M.) by a grant from CHDI, Inc. (A.J.M.). We thank Dr. Polly Taylor and Roger Mason for anesthesia and technical support, Dr. Matt Jones and Dr. Ulli Bartsch for slow-wave detection MATLAB scripts, and Dr. Vlad Vyazovskiy and Szilvia K. Vas for useful discussions.

The authors declare no competing financial interests.
}

feature prominently is many neurodegenerative disorders and are comorbid to Alzheimer disease (Musiek et al., 2015), Huntington disease (Piano et al., 2015), and neuronal ceroid lipofuscinosis (NCL; Veneselli et al., 2000).

NCLs, also collectively known as Batten disease, are a group of progressive neurodegenerative diseases each caused by a number of different mutations in at least 14 different genes (Mole and Cotman, 2015). They are characterized by the accumulation of lysosome-derived storage bodies in most cells throughout the

Correspondence should be addressed to Professor A.J. Morton, Department of Physiology, Development and Neuroscience, University of Cambridge, Downing Street, Cambridge CB2 3DY, UK. E-mail: ajm41@cam.ac.uk. DOl:10.1523/JNEUROSCI.4295-15.2016

Copyright $\odot 2016$ the authors $\quad 0270-6474 / 16 / 368238-12 \$ 15.00 / 0$ 
body (Palmer, 2015a). Neurodegeneration of the cortex is particularly pronounced (Radke et al., 2015). Clinical symptoms include visual defects, motor abnormalities, epileptiform seizures, dementia, and sleep abnormalities, which increase in severity until the premature death of the patients (Santavuori et al., 2000; Mole et al., 2011). Caregivers of Batten disease patients report that sleep abnormalities are among the most severe challenges to patient management (Malcolm et al., 2012). Investigations of sleep abnormalities show that difficulty in falling asleep, frequent awakenings, nightmares, and night terrors are the most common sleep symptoms experienced (Santavuori et al., 1993). Single night EEG recordings on children with Batten disease showed reductions in total sleep time and sleep efficiency and an increase in the amount of time spent in early non-REM (NREM; stage1) and late slow-wave sleep (stages 3 and 4; Kirveskari et al., 2000). To what extent such sleep deficits contribute to the deterioration of the patient is currently unknown. Further investigation is warranted, especially because the brain regions that give rise to slowwave activity (SWA; neocortex and thalamus) are also reported to be affected in the CLN5 variant of the disease (Holmberg et al., 2000; Radke et al., 2015) and in a CLN5 mouse model (von Schantz et al., 2009).

Here, we used the ovine model of the CLN5 variant lateinfantile NCL, which is caused by a consensus splice site mutation leading to excision of exon 3 (Frugier et al., 2008). Behavioral changes have been reported at the age of 10-11 months in these sheep and cerebral atrophy is advanced at 19 months (Amorim et al., 2015). They reach a humane end point at between 2 and 3 years of age. No studies of neuropathology of CLN5 ${ }^{-1-}$ sheep aged $<19$ months have been published, with the exception of a reported storage pathology in prenatal cell cultures (Hughes et al., 2014). In a previous EEG investigation using this sheep line, we observed NREM sleep abnormalities (Perentos et al., 2015). Although we observed depressed slow-wave oscillations, it remained unclear whether this effect was a generalized stateindependent EEG feature arising from brain atrophy or a more sleep-specific effect. To investigate this, we designed a study to challenge sleep homeostatic processes in Batten disease sheep to dissociate these two possibilities.

Sleep homeostasis refers to the propensity of sleep intensity to dissipate across a night's sleep (Borbély, 1982). Measures of sleep homeostasis include the amount of time spent in sleep states, the degree of sleep fragmentation and SWA. SWA that occurs during NREM sleep is used as a marker for sleep intensity and can be manipulated through sleep deprivation (Borbély et al., 1981; Vyazovskiy et al., 2007). SWA is thought to reflect a preponderance of generalized hyperpolarization (Hajnik et al., 2013), counteracting to a degree the cortical synaptic strengthening that occurs during waking. Therefore, SWA magnitude is thought to reflect the magnitude of the homeostatic control process (Vyazovskiy et al., 2011). SWA is also thought to reflect the extent of cortical synaptic strengthening (Davis et al., 2011; Vyazovskiy et al., 2011).

This study had two objectives: (1) to investigate whether ovine sleep has correlates of homeostatic regulation similar to those described in other mammals and (2) to use these correlates to characterize further the nature of sleep abnormalities observed in the $\mathrm{CLN} 5^{-1-}$ sheep. We achieved these objectives through a sleep deprivation experiment.

\section{Materials and Methods}

Animals. Eight (four heterozygous $\mathrm{CLN} 5^{+/-}$unaffected carriers and four homozygous $\mathrm{CLN}^{-1-}$ affected) castrated male Borderdale sheep with a c. $571+1 \mathrm{G}>$ A splice site mutation were used in this study. The sheep were reared at Lincoln University, New Zealand, and were then transferred to the United Kingdom at an age of $90 \pm 7 \mathrm{~d}$. Breeding and rearing were performed in accordance with the Lincoln University Animal Ethics committee in compliance with the New Zealand Animal Welfare Act (1999) and in accordance with National Institutes of Health guidelines. All procedures in the United Kingdom were conducted in accordance with the UK Animals Scientific Procedures Act (1986) and the University of Cambridge Animal Welfare Ethical Review Board. Groups were age and weight matched at the time of implantation (mean age $239 \pm 8 \mathrm{~d}$ and $235 \pm 11 \mathrm{~d}$ and mean weight $38.5 \pm 6.4 \mathrm{~kg}$ and $33.9 \pm$ $5.8 \mathrm{~kg}$, for $\mathrm{CLN} 5^{+/-}$and $\mathrm{CLN} 5^{-1-}$ sheep, respectively). There is no evidence, from either humans or animals, that carrying a single copy of the mutation in CLN5 causes neurological abnormalities and human carriers are neurologically normal. Therefore, we used the CLN5 ${ }^{+/-}$ sheep as unaffected control animals. At the time of implantation, sheep from both cohorts appeared neurologically normal. Sheep from both cohorts, but in particular, CLN5 ${ }^{-1-}$ sheep, showed stable weight gains and normal locomotion and gait. We measured gait and locomotion using an automated gait testing system in these and a larger group of sheep using Gaitmat. We did not find locomotor deficits in CLN5 ${ }^{-/-}$ sheep at 10 months of age and, even in sheep aged 18 months, measured locomotor deficits were minimal (A.J.M., E. Hölzner, E. Skillings, unpublished data). Regular eye examinations by an expert veterinary ophthalmologist revealed no evidence of retinal degeneration or clinical blindness at 10 months of age (assessed by examination and retinographic scans; A.J.M., D. Williams, and N.P., unpublished data). Animals could move around their pens normally and easily locate food and water. The CLN5 ${ }^{-1-}$ sheep were indistinguishable from the CLN5 ${ }^{+/-}$sheep by observation. After implantation, one of the CLN5 ${ }^{+/-}$sheep developed chewing difficulties and was therefore euthanized. Because no additional Borderdale sheep were available, this sheep was replaced with a Welsh Mountain ewe (age at recording: $480 \mathrm{~d}$ old) to maintain a sample size of four for both cohorts. The inclusion of this sheep in the no disease group was justified by our previous findings showing that sleep EEG correlates in Welsh Mountain sheep were qualitatively similar to those of heterozygous Borderdale sheep (Perentos et al., 2015). Hereafter, we refer to the CLN $5^{+/-} /$Welsh Mountain group as "unaffected" sheep and the

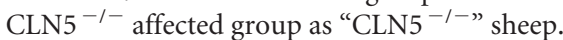

Surgery. Animals were food deprived overnight before surgery. Anesthesia induction was achieved with intravenous administration of alfaxalone (Alfaxan; Jurox) at $3 \mathrm{mg} / \mathrm{kg}$ and maintained using $2-3 \%$ isoflurane through a Manley ventilator. Throughout the surgery, end-tidal $\mathrm{CO}_{2}$ and mean arterial blood pressure were kept between 25 and $30 \mathrm{mmHg}$ and $70-90 \mathrm{mmHg}$, respectively. Vital functions were recorded at regular intervals throughout the procedure. Intravenous fluids were supplied at a rate of $5 \mathrm{ml} / \mathrm{kg} / \mathrm{h}$ (lactated Ringer's, Hartmann's Solution 11; Aquapharm).

Full details of the implantation techniques have been described in detail previously (Perentos et al., 2015). Briefly, using aseptic techniques, the dorsal surface of the skull was exposed and craniotomies were drilled at positions 30,20 , and $10 \mathrm{~mm}$ anterior and $10 \mathrm{~mm}$ posterior to the intersection of the frontal and posterior skull bones (Fig. 1A). Intracortical stainless steel needles (E6912; Watkins \& Doncaster) were then implanted through the craniotomies and secured on the skull using plastic screws. Additional anchoring stainless steel screws were implanted, as well as bipolar neck electromyogram (EMG) and bipolar electrooculogram (EOG) electrodes. All cortical electrodes were subsequently secured in place with dental acrylic containing gentamicin (Depuy CMW2; Johnson \& Johnson). All electrodes were terminated at an Omnetics Micro circular connector and exteriorized through the skin at the occiput.

Recordings. Two weeks after implantation, EEG recordings commenced as part of a longitudinal EEG assessment study that would continue for the lifespan of the implants (data not shown).

A month after electrode implantation (when sheep were 9-10 months of age), $3 \sim 24$ h recordings were collected from each animal on 3 consecutive days. Data were collected across different sets of days for different animals due to the limited number of amplifiers available (two groups of three and two groups of one). The first day served as the 
baseline and was thus free of any intervention apart from instrumentation for EEG recordings. On the second day (deprivation), the animals were sleep deprived from 4:00 P.M. until 12:00 A.M. Sleep deprivation was achieved by monitoring the animals and preventing them from sitting down or closing their eyes. If an animal was observed to be closing its eyes, an operator familiar to the sheep would enter the holding pen and approach the animal. In addition, all animals were moved from one holding pen to an adjacent one at regular $30 \mathrm{~min}$ intervals. On the third day (recovery), there were no interventions. On all $3 \mathrm{~d}$, sheep had ad libitum access to water and hay. Pelleted supplement feed was provided daily between 8:00 and 9:00 A.M. All sheep were familiar with the operators and were handled regularly so it is expected that stress levels arising from the sleep deprivation were unlikely but cannot be excluded.

Data were collected using four-channel neurologger amplifiers (NewBehavior) with a sampling rate of $256 \mathrm{~Hz}$ and filtered in the $0.5-30 \mathrm{~Hz}$ range. The devices were secured below the occiput on the neck area (Fig. 1B). Two EEG channels were referenced to an occipital electrode and one neck EMG channel and an EOG channel were both referenced to a neck EMG channel. This resulted in a bipolar neck EMG channel and a composite EMG/EOG channel serving as an EEG-free channel that allowed us to detect eye movements and chewing related artifacts. Between 9:00 and 10:00 A.M. each day, the amplifiers were removed, data were downloaded, and the amplifiers were reattached by 10:00 A.M.

Vigilance state classification. Recordings were "epoched" into 10 s intervals and each was manually assigned to one of five vigilance states (wake, rumination, rumination with concurrent NREM, NREM, and REM; Fig. $1 C-G$ ). Epochs containing artifactual signals precluding the assignment to a vigilance state were classified as "undefined". Wake epochs were defined by low-amplitude desynchronized EEG activity accompanied by high muscle tone. Rumination epochs were defined by wake-like EEG accompanied by regular mastication artifacts on the EOG channels. Rumination with concurrent NREM epochs (RUM + NREM) was defined by slow, high-amplitude EEG oscillations, reduced muscle tone, and regular mastication artifacts on the EOG channel. NREM epochs were defined by slow, high-amplitude EEG oscillations, reduced EMG muscle tone, and an artifact-free EOG activity. REM epochs were defined by wake-like EEG, a predominantly flat EMG, and flat EOG with occasional eye-movementrelated voltage deflections and were always preceded by NREM epochs. During REM sleep, a characteristic sudden muscle twitch was visible occasionally during otherwise flat EMG; muscle twitches during REM sleep have been reported in previous animal sleep studies, including studies in sheep (Brisbare-Roch et al., 2007; Beuchée et al., 2012).

Assessment of deprivation, rebound, and fragmentation effects. From each day's recording, three time intervals were extracted and used for comparisons. These were the predeprivation interval (12:00-4:00 P.M.; period 1), the period corresponding to the sleep deprivation time of the second experimental day (5:00 P.M.-12:00 A.M.; period 2), and a recovery interval corresponding to the hours after sleep deprivation (12:005:00 A.M.; period 3). The 4:00-5:00 P.M. interval was not included in the analyses to avoid small differences in onset/offset of recording $(< \pm 1 / 2$ h) from contaminating the deprivation period data. We compared the same time-of-day intervals across days, thereby avoiding any effect arising from circadian time differences. To assess the effectiveness of sleep deprivation, we compared period 2 of the baseline day with period 2 of the sleep deprivation day. The presence of a sleep rebound effect was assessed by comparing the amount of time spent in the NREM state during period 3 of the baseline and sleep deprivation days.

EEG analysis. Spectral analysis was performed in MATLAB R2015a (The MathWorks) using the Chronux MATLAB toolbox, implementing 5 tapers, a time-bandwidth product of 3 , and a rolling window of $5 \mathrm{~s}$ with no overlap (Bokil et al., 2010). NREM epochs containing artifacts were excluded from spectral analysis. This was achieved semiautomatically by standardizing the waveform and excluding any epoch with values exceeding \pm 6 SDs. For one sheep, additional rejection was necessary because of a high frequency of artifacts. For the baseline day, independent components analysis (ICA) was used to remove most of the ruminationrelated chewing activity contaminating the EEG channels. This ICA 
A
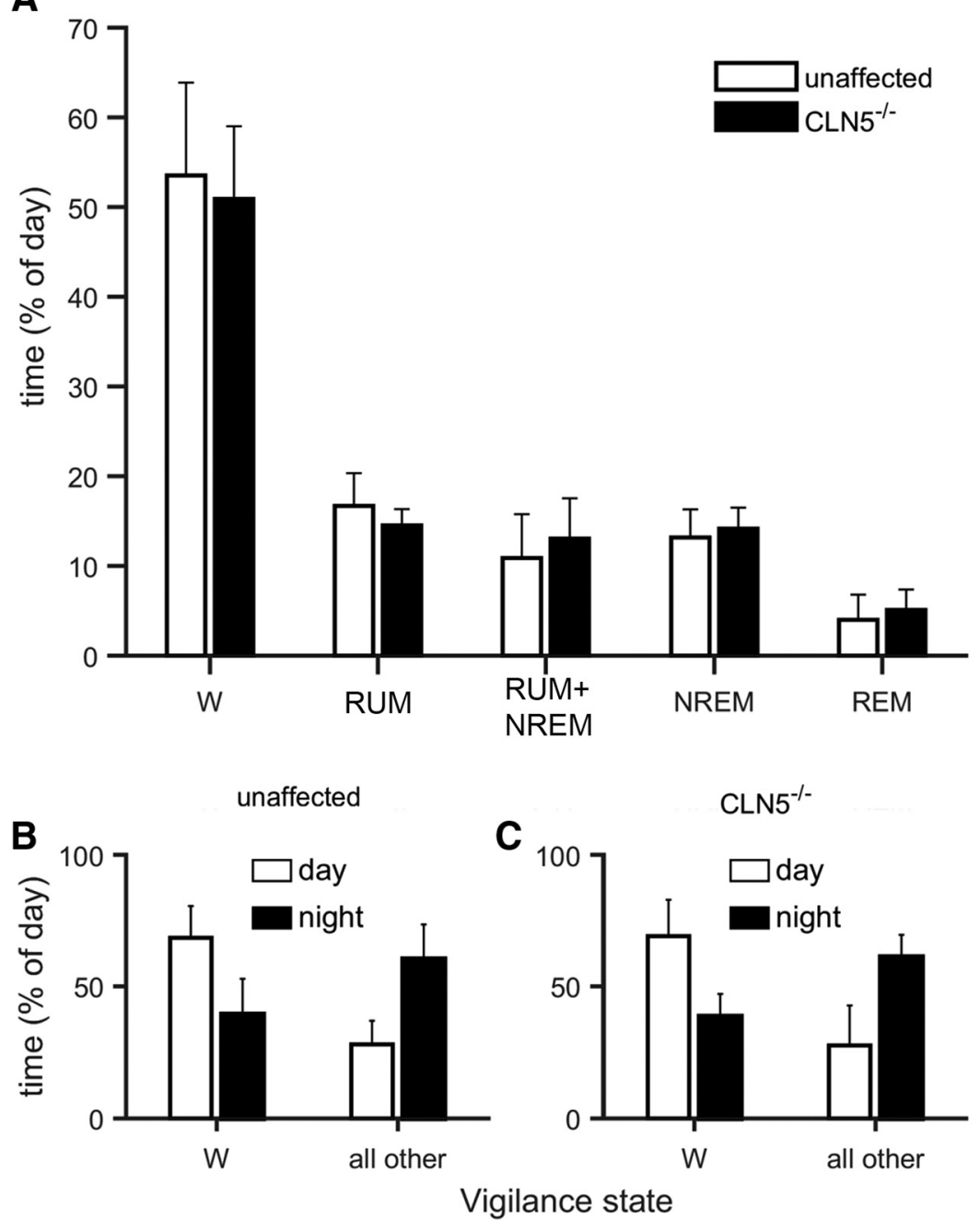

Figure 2. Both groups of sheep show similar sleep-wake profiles. $A, 0$ n the baseline day, the times spent in each vigilance state were similar between unaffected (open bars) and CLN5 ${ }^{-1-}$ (black bars) sheep. $\boldsymbol{B}, \boldsymbol{C}$, Unaffected (B) and CLN5 ${ }^{-1-}$ ( $\boldsymbol{C}$ ) sheep exhibited diurnal activity patterns, with more time spent in wakefulness during daytime (open bars) compared with nighttime (black bars).

correction was applied throughout the baseline day recordings; however, it was mostly relevant for epochs with rumination (RUM or RUM + NREM). EEG power spectra were then computed for all states. To assess whether delta-band power was increased after sleep deprivation compared with the same time interval of the baseline day, spectral power data from NREM epochs were compared across these $2 \mathrm{~d}$. Because the absolute spectral powers differed between sheep, we standardized these spectral powers on a per-subject basis. This was achieved by collapsing the data across the $2 \mathrm{~d}$ to form a single distribution that was then standardized ( $z$-scored) so as to have a zero mean and an SD of 1 . The $z$-scored epochs were then regrouped according to experimental day with the a priori expectation that, if postdeprivation spectra were to be higher, then they would occupy the upper end of the $z$-scored distribution, whereas the predeprivation spectra would occupy the lower end of this normal distribution. Using this method, we obtained similar results to those from raw data spectral powers (data not shown).

To analyze the distribution of the amplitudes of slow-wave oscillations and their temporal relationship with respect to spindle band activity, slow-wave oscillations from NREM epochs with waveforms filtered in the delta band $(0.5-4 \mathrm{~Hz})$ were detected using a threshold detection algorithm. Detections exceeding 2 SDs were used. We detected both positive- and negative-going slow waves. These were subdivided into waves with a subsequent negative deflection, subsequent positive deflection, or no additional deflection. To assess further the influence of ho- meostatic control over the amplitude of slow waves during NREM sleep, we compared slowwave amplitudes and NREM spectral power in the delta band between the first half of the period 3 (12:00-2:30 A.M.) with the second half (2:30-5:00 A.M.). We hypothesized that larger slow-wave amplitudes would be found in the first half. We also computed the maximum slope for each detected slow wave and contrasted these slopes between the first and second half time intervals described above.

Spindle band activity during NREM sleep is temporally grouped by slow-wave oscillations (Contreras and Steriade, 1995; Mölle et al., 2002). Using baseline day NREM sleep data, we compared the degree of this temporal grouping between the two cohorts of sheep using triggered spectrograms of spindle-filtered waveforms $(10-15 \mathrm{~Hz})$ centered on the time points of the peaks of the detected slow waves. The epoch of -0.5 to $+0.5 \mathrm{~s}$ around the slow-wave peak with a sliding window of $0.25 \mathrm{~s}$ and an overlap of $0.05 \mathrm{~s}$ was used for spectrogram generation.

Statistical analysis. To assess differences in the amounts of time spent in each state, a twoway ANOVA was used. Diurnality was assessed through paired sample $t$ tests comparing the amount of time spent in non-awake states during daytime (8:00 A.M.-7:00 P.M.) with that spent during nighttime (7:00 P.M.-8:00 A.M.). Differences in diurnality between the two sheep cohorts were assessed through independent-samples $t$ test with the independent variable being the time spent in sleep states during daytime minus the time spent in sleep states during nighttime. A repeatedmeasures ANOVA across the 3 experimental days was used to assess sleep deprivation effects on the amount of time spent in the NREM state. Although an omnibus ANOVA was used, tests of reduced NREM during deprivation intervals and increased NREM after deprivation were treated as a priori hypotheses with no multiple-comparisons corrections applied. All other comparisons were considered exploratory and were subjected to post hoc Bonferroni corrections for multiple comparisons. Sleep fragmentation effects were assessed using Wilcoxon signed-rank tests. Hypothesis-driven tests of higher delta power, higher slow-wave amplitude, and steeper slopes for early versus late sleep times were tested using Wilcoxon signed-rank tests for related samples. Results were considered significant at $p<0.05$.

\section{Results}

\section{Unaffected and CLN5 $5^{-/-}$sheep exhibit diurnal} activity patterns

On the baseline day, both unaffected and CLN5 ${ }^{-1-}$ sheep spent similar amounts of time in each vigilance state (Fig. $2 A$, two-way ANOVA with no main effect of sheep group, $F<0.4$, df $=1, p>$ 0.94 , and no interaction between vigilance state and sheep group, $F<0.4, \mathrm{df}=1, p>0.84)$. Consistent with our previous findings, both unaffected and CLN $5^{-1-}$ sheep showed diurnal activity patterns, with all sheep spending significantly more time in nonawake states during the nighttime (Fig. $2 B, \mathrm{C} ; t=-4.624 \mathrm{df}=3$, $p=0.019$ and $t=-3.399, \mathrm{df}=3, p=0.042$ for unaffected and $\mathrm{CLN}^{-1-}$ sheep, respectively). There was no difference in diurnality between the 2 groups $(t=0.103, \mathrm{df}=6, p=0.922)$. Figure $4 A-C$ shows example hypnograms for an unaffected sheep across 
A

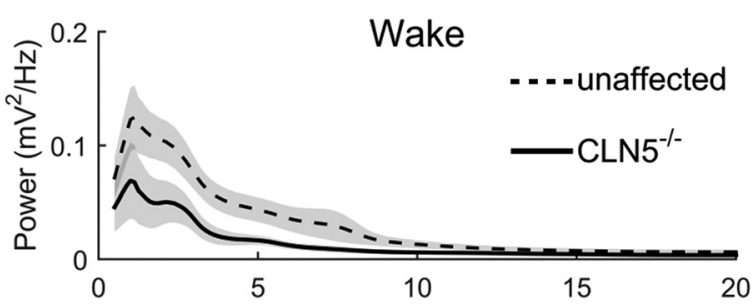

B

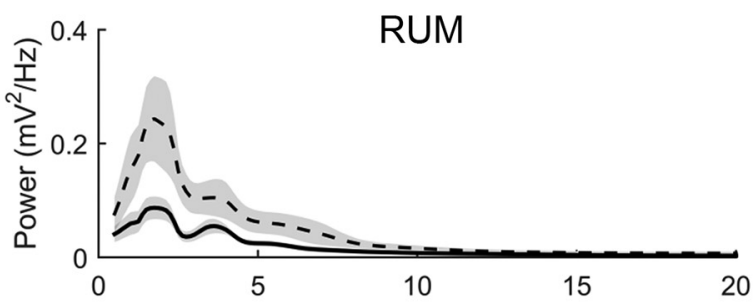

C

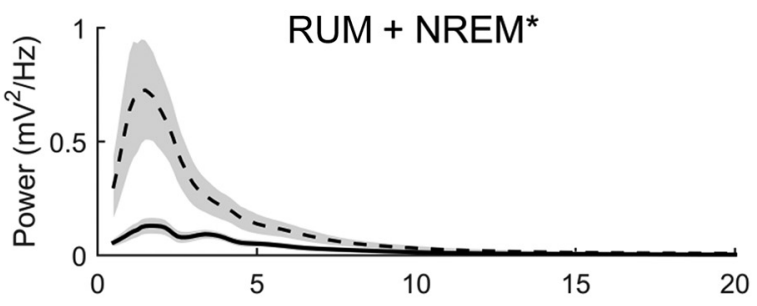

D
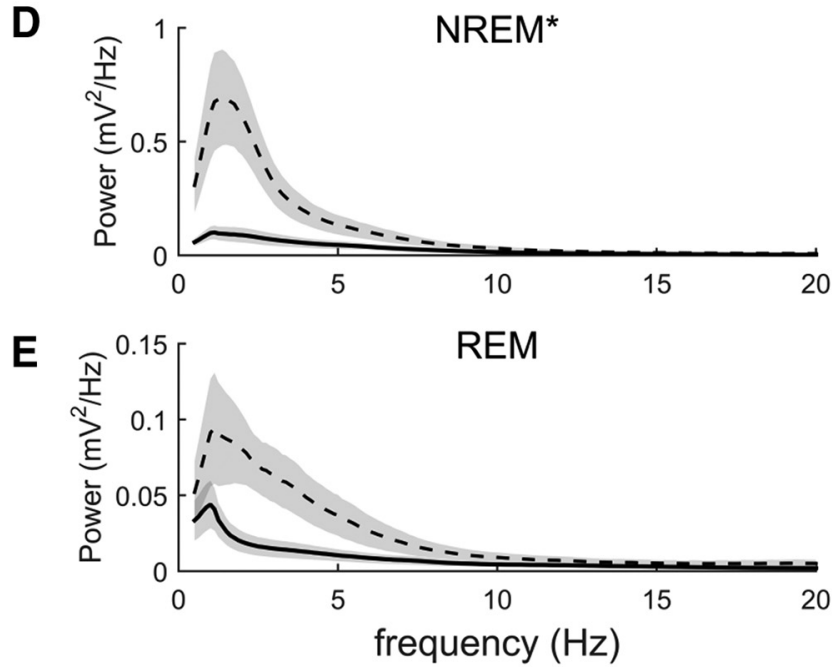

Figure 3. Lower spectral powers were observed in NREM-associated states for CLN5 ${ }^{-1-}$ sheep. Baseline day group average spectra (averaged across both cortical electrodes) are shown for wakefulness $(\boldsymbol{A})$, rumination $(\boldsymbol{B})$, rumination during NREM sleep $(\boldsymbol{C})$, NREM sleep $(\boldsymbol{D})$, and REM sleep $(\boldsymbol{E})$. Lower-power spectra are observed throughout all stages in CLN5 ${ }^{-1-}$ sheep and significantly lower for the RUM + NREM and NREM states; ${ }^{*} p<0.05$.

the 3 experimental days. Similar hypnograms were obtained for all sheep (data not shown).

Reduced power in baseline EEG spectra in CLN5 ${ }^{-/-}$sheep On the baseline day, rumination-free EEG spectra for all vigilance states were computed across the two available EEG electrodes and compared across subjects. Although a generally lower power was observed in the CLN5 ${ }^{-1-}$ sheep throughout all states, this effect was significant only for the states of RUM + NREM and NREM (Fig. 3; Wilcoxon rank-sum tests: wake: $Z=2.363, p=0.09$; RUM: $Z=1.943, p=0.260$; RUM + NREM: $Z=2.678, p=$ 0.037; NREM: $Z=2.783, p=0.027$ and REM: $Z=2.363, p=$ 0.09 ; with 2 electrodes per subject treated as independent obser- vations; $p$-values are Bonferroni corrected). These results are consistent with our previous findings (Perentos et al., 2015). Our previous study indicated a comparatively increased $3-5 \mathrm{~Hz}$ activity in normalized NREM spectra of CLN5 ${ }^{-1-}$ sheep. We therefore investigated whether this was the case in the present cohort. NREM spectra for each sheep were normalized to unity (i.e., spectral amplitudes at each frequency bin were divided by the total amount of power in the $0.5-25 \mathrm{~Hz}$ interval, yielding a total area under the curve equal to one for both cohorts, thereby removing any effects of pure power level differences between groups). Although there was a trend toward an increased $3-5 \mathrm{~Hz}$ activity, this effect was not significant (one-tailed Wilcoxon ranksum test $=12, p=0.057$ ).

\section{Sleep deprivation leads to NREM rebound}

To assess sleep deprivation effects on the amount of NREM sleep, a repeated-measures ANOVA was used, with one betweensubjects factor (unaffected vs CLN5 ${ }^{-/-}$) and two within-subjects factors (experimental day and time of day). There were significant main effects for the factors of experimental day $(F=37.94$, $\mathrm{df}=2, p<0.001)$, as well as significant interactions between experimental day and time of day $(F=33.30, \mathrm{df}=4, p<0.001)$. Hypothesis-driven tests revealed an effective sleep deprivation for both groups, with significantly less time spent in the NREM state in period 2 of the deprivation day, compared with period 2 of the baseline day (Fig. 4E, unaffected: $t=6.74, \mathrm{df}=3, p=0.007$ and CLN5 $\left.{ }^{-1-}: t=3.76, \mathrm{df}=3, p=0.033\right)$. Similarly, there was a statistically significant increase for both groups in the amount of time spent in the NREM state during period 3 on the sleep deprivation day compared with period 3 of the baseline day (Fig. $4 F$; unaffected: $t=3.19, \mathrm{df}=3, p=0.050$ and CLN5 ${ }^{-1-}: t=6.08$, $\mathrm{df}=3, p=0.009$ ). There were no main effects of group or interactions between group and either experimental day or time of day. Further exploratory tests revealed no differences in period 1 of any of the experimental days (Figure $4 D$ ) or any recovery day effects for both periods 2 and 3.

The degree of fragmentation of NREM sleep is thought to reflect sleep pressure and has been shown to be under homeostatic influence (Baud et al., 2015). We therefore calculated the average sleep bout duration within period 3 of each day. Compared with the baseline day, on the sleep deprivation day there was a significant increase in the average NREM bout duration in both groups of sheep (Fig. $5 A, B$, unaffected: $p=0.0143, Z=$ 2.165 CLN5 $^{-1-}: p=0.014, Z=2.165$; both tests were one-tailed with a priori hypothesis of increased bout duration). On the recovery day, the average bout duration dropped to baseline levels in the unaffected sheep (two-tailed test, $Z=1.01, p=0.312$ ). However, there remained a significant elevation of bout length in the CLN5 ${ }^{-1-}$ sheep during the recovery day (Fig. 5B, two-tailed test, $Z=-2.165, p=0.03)$. There were no between-subject differences for time spent in the NREM state in either sleep deprivation or recovery days. Together, the results of increased duration of NREM sleep and increased NREM sleep bout length point to the presence of homeostatic regulation of sleep in both unaffected and CLN5 ${ }^{-1-}$ sheep after an 8 h sleep deprivation. Exploratory tests for sleep-deprivation-induced effects were conducted for the states of RUM, RUM + NREM, and REM. There were no statistically significant changes observed for these states, in either experimental day by time of day interactions or grouprelated interactions. 
A

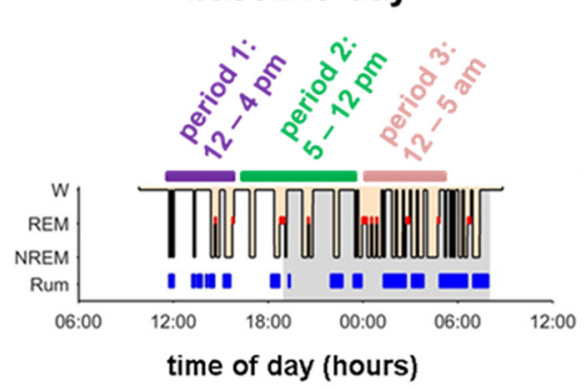

D

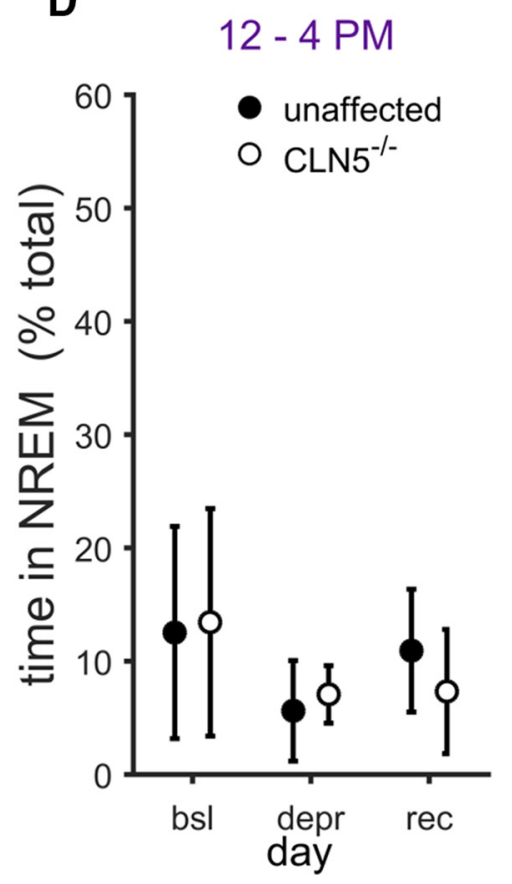

B sleep deprivation day

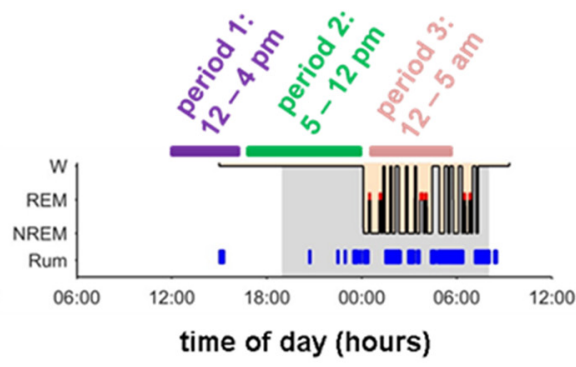

C

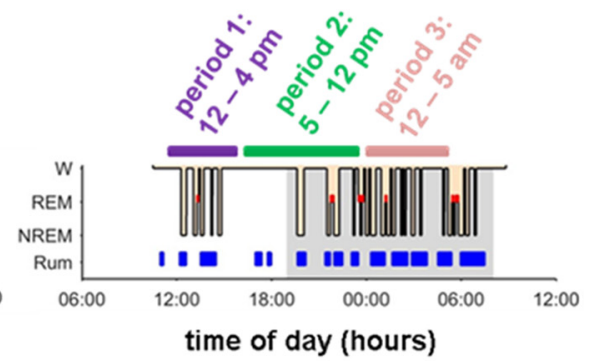

E

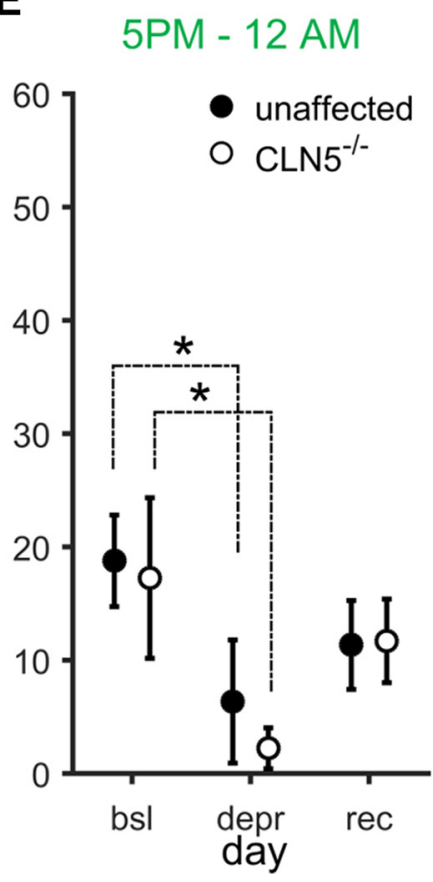

F
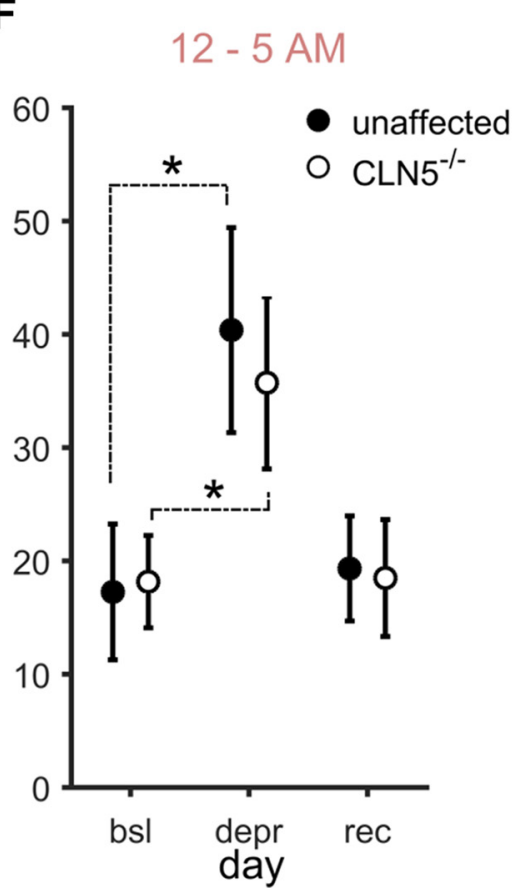

Figure 4. Sleep deprivation led to a distinct rebound in NREM sleep amount. $\boldsymbol{A}-\boldsymbol{C}$, Twenty-four hour hypnograms from an unaffected sheep are shown for baseline day ( $\boldsymbol{A}$ ), sleep deprivation day $(\boldsymbol{B})$, and recovery day $(\boldsymbol{C})$. Rumination intervals, regardless of concurrent slow-wave EEG activity, are marked with blue rectangles and REM sleep periods are marked with red rectangles. $\boldsymbol{D}$, Between the hours of 12:00 and 4:00 P.M., there was no difference in NREM sleep amounts between experimental days. $\boldsymbol{E}$, Reduced time in the NREM state was observed during the sleep deprivation interval. $\boldsymbol{F}, \mathrm{A}$ rebound in the amount spent in the NREM state was observed between 12:00 and 5:00 A.M. immediately after sleep deprivation. Gray area represents the nighttime period. Data are mean $\pm \mathrm{SEM} ;{ }^{*} p<0.05$.

\section{Absence of SWA rebound in the CLN5 ${ }^{-1-}$ sheep}

A strong indicator of a response to increased sleep homeostatic pressure is an increase in spectral power in the EEG delta band during the NREM sleep state (Borbély et al., 1981). Although unaffected sheep showed a robust increase in this measure after sleep deprivation (Fig. $6 A$, delta-band power change $0.97 \pm 0.62$ $\mathrm{SD}, Z=2.165, p=0.03)$, there was no such response in 3 out of 4 CLN $^{-l-}$ sheep (Fig. $6 C$, delta-band power change $-0.04 \pm$ $0.32 \mathrm{SD}, Z=0.436, p=0.66)$. The exception was a CLN5 ${ }^{-1-}$ sheep that showed an unusually high delta power increase. After closer inspection of the EEG recording of the sleep deprivation day for that animal, an increased amount of slow $(<1 \mathrm{~Hz})$ activity was observed across all channels, including EMG and EOG channels (data not shown). Because this increase was not specific to the EEG channels, it was considered artifactual. Therefore, this animal was excluded from this analysis step. Finally, for both groups, the delta-band spectral power of the recovery day did not differ from the baseline day (Fig. $6 B, D$ ). Note the apparent discrepancy between the raw amplitudes of Figure 3 and the $z$-scored spectra here. This arises from the $z$-scoring procedure that was optimized for within group comparisons versus the raw data of Figure 3 that captures the raw spectral power-level differences between the two groups.

\section{Abnormal grouping of spindle band activity by SWA in CLN5 $^{-/-}$sheep}

SWA has been reported to influence the timing of spindle band activity in humans and other animals (Contreras and Steriade, 1995; Mölle et al., 2002; Vyazovskiy et al., 2011). The site of generation of spindles is commonly thought to be the thalamus, whereas a two-way interaction with the cortex seems to shape the properties of these events (Bonjean et al., 2011). Therefore, we examined the timing characteristics of sleep spindles with respect to slow-wave oscillations. Using data from the baseline day, slowwave events exceeding 3 SDs were detected from each sheep's delta-band-filtered EEG $(0.5-4 \mathrm{~Hz})$. Both positive-going (Fig. $7 A, B$ ) and negative-going (Fig. 7C,D) slow waves were detected. These were subdivided into two categories: those that were followed by a voltage deflection in the opposite direction and those that were not. For 2 out of 4 CLN5 ${ }^{-/-}$sheep, the detection limits 
needed to be reduced to 2 SDs to allow sufficient detections, whereas, for another $\mathrm{CLN} 5^{-1-}$ sheep, only positive and negative waves without a subsequent deflection in the opposite direction were detected. Using a one-way ANOVA, all four types of waves were found to have significantly lower amplitude in CLN5 ${ }^{-1-}$ sheep [dependent variable was the sum of absolute amplitudes from -0.25 to $0.25 \mathrm{~s}$ around the detected slow-wave peaks; negative waves followed by a positive deflection $(F=8.324, p=$ 0.028 ); positive waves followed by a negative deflection $(F=$ $12.704, p=0.012)$; negative waves $(F=12.004, p=0.013)$, and positive waves $(F=13.387, p=0.011)]$. Average triggered spectrograms centered on the main peak of the detected slow waves revealed a grouping of spindle band activity by SWA in unaffected sheep (Fig. $7 E-H$ ). This grouping was strongest for negative-going waves, followed by a positive voltage deflection. It was absent from $\mathrm{CLN}^{-1-}$ sheep triggered spectrograms, particularly for negative-going slow waves (Fig. $7 I, J$ ), revealing an abnormal temporal coordination of these two electrophysiological signatures.

\section{Homeostatic regulation of SWA}

In humans and rodents, sleep pressure dissipates throughout sleep (Bersagliere and Achermann, 2010; Vyazovskiy et al., 2011). Accordingly, early NREM sleep contains SWA of higher amplitude compared with late NREM. Examples of this can be seen in Figure 8, $A$ and $B$, where early NREM epochs seem to follow a similar trend. To quantify this in sheep, we focused on period 3 of the sleep deprivation day and compared the NREM activity of the first $2.5 \mathrm{~h}$ of this interval (early: 12 : 30-2:30 A.M.) with the second $2.5 \mathrm{~h}$ (late: 2:30-5:00 A.M.). We quantified early versus late SWA in terms of the average delta power, average amplitude of detected slow waves, and average slope of slow waves. Spectral amplitudes and slow-wave amplitudes were $z$-scored on a per-animal basis to allow for an early/late comparison across animals. The expectation was that, if there was an early/late delineation in these measures, then high- and low-amplitude spectra or slow waves would not be equally distributed across the $5 \mathrm{~h}$ interval. After this standardization, the data were split into early and late periods and the total numbers of epochs with spectra exceeding the average power were contrasted between early and late epochs. We found three major differences. First, in unaffected sheep, early sleep had significantly more high-power spectra than late sleep (Fig. $8 C$; mean decrease from early-to-late: $34.64 \pm 4.49 \%$, $Z=1.826, p<0.034$, one-tailed test). However, this early versus late distribution bias was absent from the $\mathrm{CLN}^{-1-}$ sheep (Fig. $8 D$; mean decrease: $0.22 \pm 14.34 \%, Z=-0.365, p>0.450$, one-tailed test). Second, there was a significant difference in the slow-wave amplitude distributions in unaffected sheep, with early epochs containing more high-amplitude slow waves than the late epochs (Fig. $8 E$; mean $z$-score decrease: $0.30 \pm 0.11, Z=$ $1.826, p<0.034$, one-tailed test). Again, this effect was absent in the CLN5 ${ }^{-1-}$ sheep (Fig. $8 F$; mean decrease: $0.02 \pm 0.13 \%, Z=$ $0.730, p=0.233$, one-tailed test). Finally, slow-wave slopes of
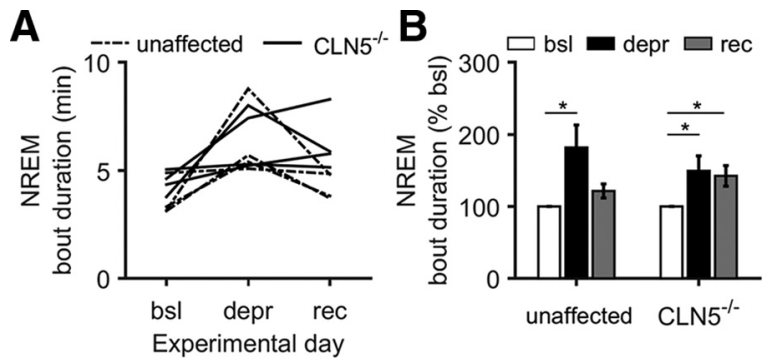

Figure 5. Increased sleep bout lengths are observed after sleep deprivation. A, Mean sleep bout length for each sheep is shown for the time interval of 12:00-5:00 A.M. across the 3 experimental days. $\boldsymbol{B}$, Mean sleep bout durations across the 3 experimental days are shown. Both cohorts showed elevated sleep bout duration in period three of the sleep deprivation day versus period 3 of the baseline day. Although period 3 of the recovery day returned to baseline levels in unaffected sheep, this remained elevated in CLN5 ${ }^{-1-}$ sheep; ${ }^{*} p<0.05$.
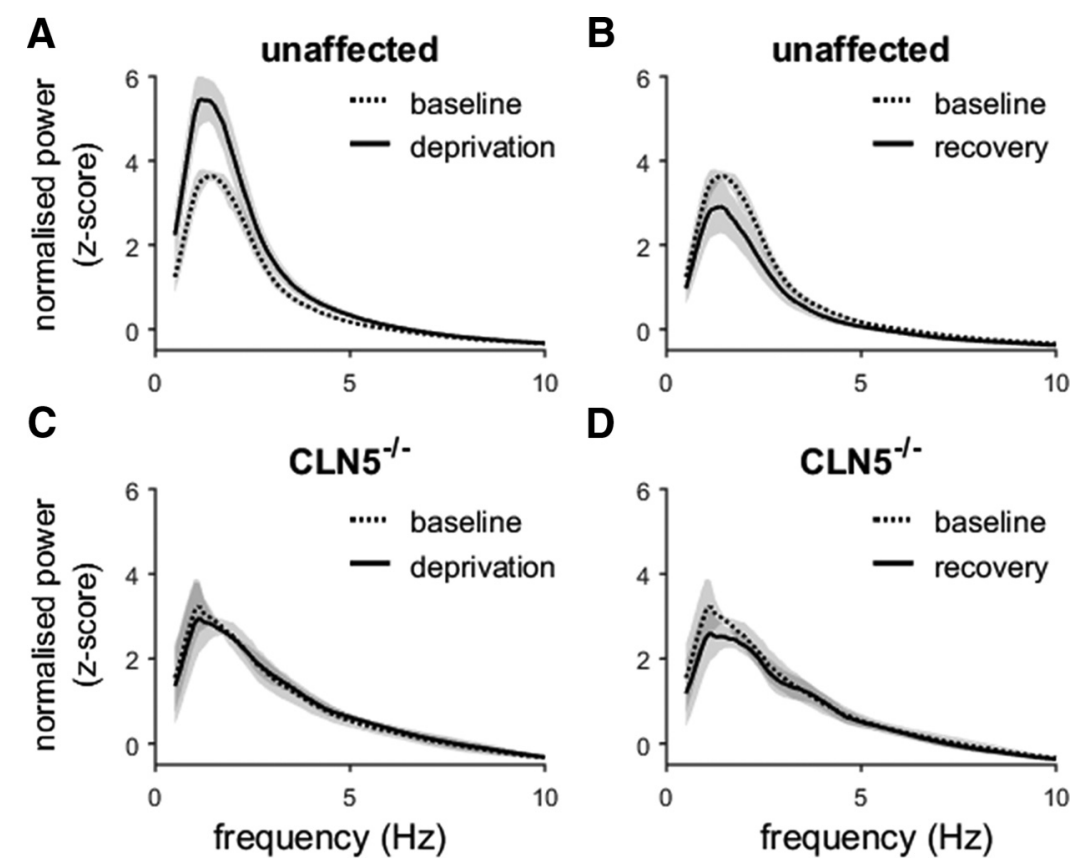

D

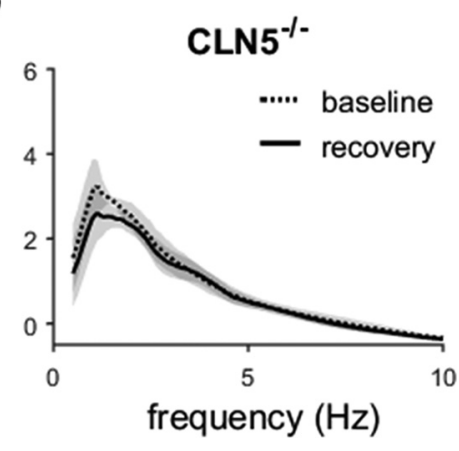

Figure 6. NREM delta power increased in unaffected but not $\mathrm{CLN}^{-1-}$ sheep in the interval immediately after sleep deprivation (12:00 -5:00 A.M.). Baseline versus deprivation day normalized EEG spectral powers are shown for the unaffected sheep in $\boldsymbol{A}$ and for the CLN5 ${ }^{-1-}$ sheep in C. Baseline versus recovery day normalized EEG spectral powers are shown for the unaffected sheep in $\boldsymbol{B}$ and for the CLN5 ${ }^{-1-}$ sheep in $\boldsymbol{D}$.

unaffected sheep showed an early-to-late decrease (Fig. 8G; mean decrease: $4.24 \pm 1.61 \mu \mathrm{V} / \mathrm{s}, Z=1.826, p<0.034$, one-tailed test). This effect was absent in the CLN5 ${ }^{-1-}$ sheep (Fig. $8 H$; mean decrease: $1.05 \pm 1.31 \mu \mathrm{V} / \mathrm{s}, Z=0.354, p>0.715$, one-tailed test).

\section{Large-scale atrophy observed in CLN5 ${ }^{-1-}$ sheep}

Because we were unable to obtain the brain tissue from these animals at the time of this experiment (as the animals were part of a longitudinal study spanning their whole lifespan), we cannot assert the level of degeneration that was present at the time of recording. However, we did investigate the gross neuroanatomical structure of the postmortem brains to ensure that the expected gross structural abnormalities were present in the $\mathrm{CLN}^{-1-}$ sheep. Figure 9 shows clearly profound cortical atrophy in the CLN5 ${ }^{-1-}$ sheep that was completely absent from either stock animals or heterozygous unaffected $\mathrm{CLN}^{+/-}$sheep. Furthermore, an MRI-based volumetric comparison of a $\mathrm{CLN}^{-/-}$brain with an "average" brain derived from an ex vivo 

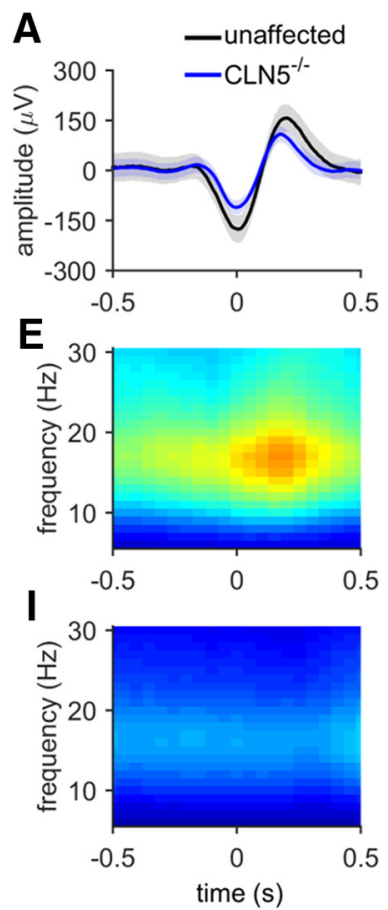

B

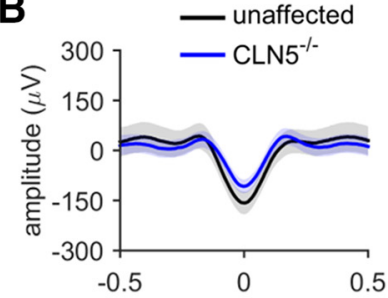

F

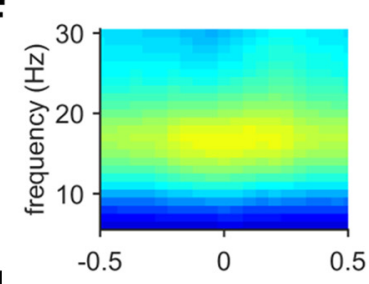

J

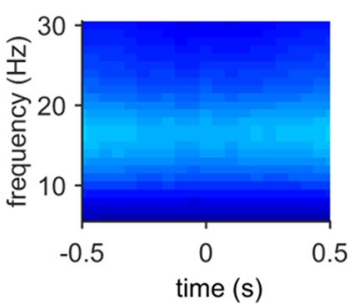

C

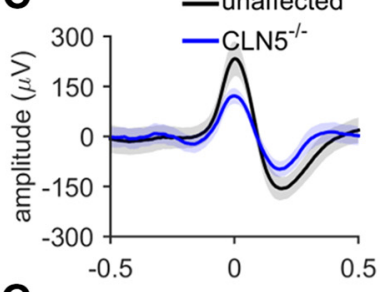

G

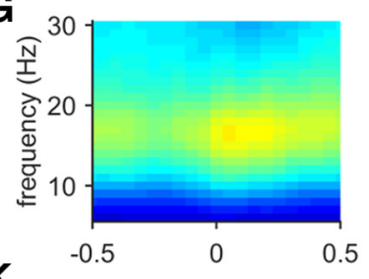

K

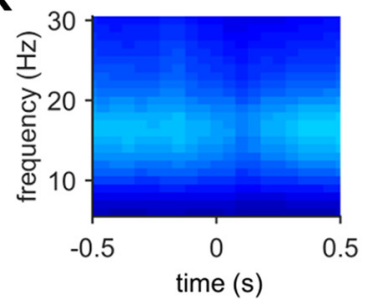

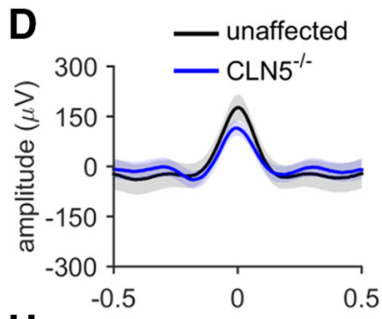

H

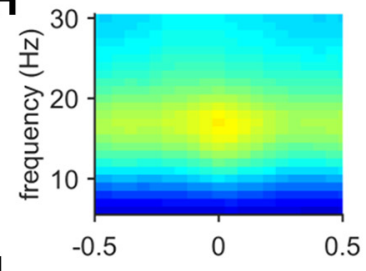

L

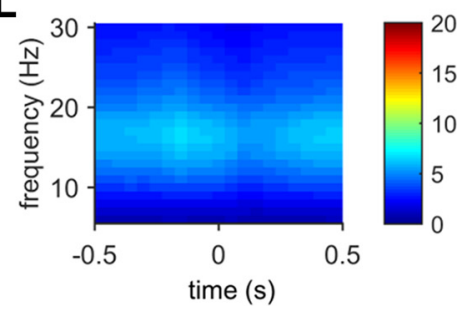

Figure 7. Spindle band $(10-15 \mathrm{~Hz})$ activity is gated by slow-wave oscillations in unaffected sheep, but is disrupted in CLN5 ${ }^{-/-}$sheep. Threshold-detected slow-wave averages detected within NREM epochs of the baseline day are shown for unaffected and $\mathrm{CLN}^{-1-}$ sheep $(\boldsymbol{A}-\boldsymbol{D})$. Respective average triggered spectrograms around the peaks of these slow waves for unaffected sheep $(\boldsymbol{E}-\boldsymbol{H})$ and $\mathrm{CLN} 5^{-/-}$sheep $(\boldsymbol{I}-\boldsymbol{L})$ reveal distinct modulation of spindle-band activity by the slow-wave oscillations. The overall amplitude of the spindle-band oscillations of $\left(\mathrm{LN}^{-1-}\right.$ are lower than their unaffected counterparts. Temporal modulation of the spindle band is evident in all detected wave types of unaffected sheep $(\boldsymbol{E}-\boldsymbol{H})$, whereas it is completely absent from CLN5 ${ }^{-1-}$ negative-going slow waves $(\boldsymbol{I}, \boldsymbol{J})$ and temporally shifted in positive-going slow waves $(\boldsymbol{K}, \boldsymbol{L})$. All data are from baseline day recordings and spectrograms are derived from high-pass-filtered $(>8 \mathrm{~Hz})$ waveforms.

A

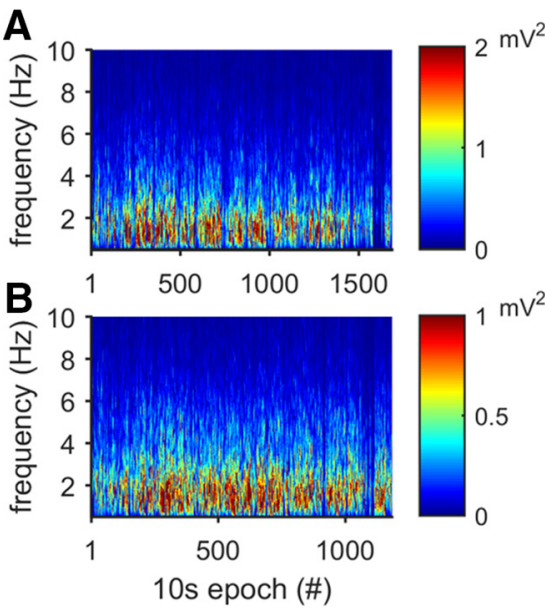

C

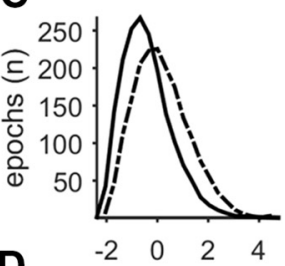

D

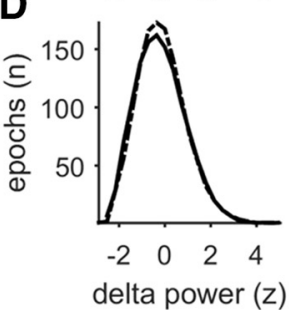

E
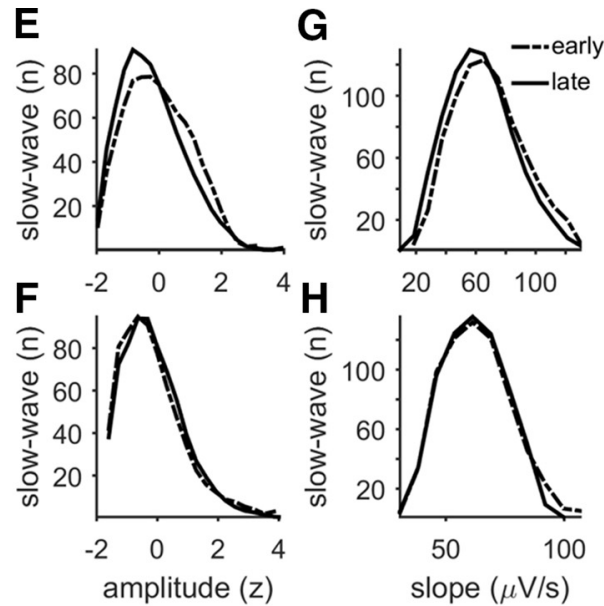

Figure 8. NREM sleep EEG variables are under homeostatic control in the unaffected but not in the CLN5 ${ }^{-1-}$ sheep. Example NREM power spectra are shown for an unaffected sheep $(\boldsymbol{A})$ and a CLN5 $^{-1-}$ sheep (B) from the 12:00 -5:00 A.M. time interval of the baseline day (with all NREM epochs of the baseline day concatenated together). After sleep deprivation (period 3 of the sleep deprivation day), early NREM epochs (12:00 -2:30 A.M.; dashed lines) show greater delta-band power (C), slow-wave amplitude (E), and slow-wave slope (G) than late NREM epochs (2:30 -5:00 A.M.; solid lines). These early/late profiles are absent in $\mathrm{CLN}^{-1-}$ sheep $(\boldsymbol{D}, \boldsymbol{F}$, and $\boldsymbol{H}$, respectively).

sheep MRI brain atlas $(n=78)$ revealed a volume reduction of both the cerebral cortex and the thalamus, as well as an enlargement of the ventricles (Fig. 10). The observed cortical atrophy is consistent with the generalized reduction in EEG amplitude across states that is observed in CLN5 ${ }^{-l-}$ sheep.

\section{Discussion}

Sheep as an animal model for brain function studies

Large animals, in particular farm animals such as sheep, offer novel opportunities as models for neurological function and dysfunction (Morton and Howland, 2013; Chang et al., 2015). Sheep are easily managed and have significant advantages over rodents, particularly in relation to their brain anatomy (having large gyrencephalic cortices) and their lifespan (living for at least 10 years). The extended lifespan is particularly useful when studying late-onset diseases such as Huntington disease, in which a long (several years) subtly phenotypic premanifest stage precedes clinical diagnosis (Tabrizi et al., 2013). Due to their extended lifespan, correctly engineered transgenic sheep 
would also feature a longer premanifest stage, which can be used to study disease progression in a translationally meaningful time frame (Morton et al., 2014).

\section{Sleep homeostasis in unaffected and $\mathrm{CLN}^{-1-}$ sheep}

Here, we showed for the first time that sleep in sheep is under the influence of homeostatic regulation. The nature of this regulation is similar to that of other species, including humans (Borbély et al., 1981; Huber et al., 2004; Vyazovskiy et al., 2011). After sleep deprivation, we found significant increases in SWA and decreases in the degree of sleep fragmentation and duration in unaffected sheep. In addition, the well known profile of decreasing SWA throughout a night's sleep, commonly considered to be a measure of the dissipation of sleep pressure (Borbély, 1982), was replicated in unaffected sheep. These results confirm the homeostatic control of sleep in sheep and expand the repertoire of uses of sheep as a model for brain function to include sleep and sleep dysfunction. The measure of sleep onset latency, also an indicator of sleep pressure (Carskadon and Dement, 1979), was not assessed here, but would be an interesting addition to the reported measures. This is particularly so given the translational relevance of this measure. Coupled with the diurnal nature of the sheep wake/rest cycle and evidence from other studies (Tobler et al., 1991; Morton et al., 2014), the results detailed here fit within the twoprocess model of sleep regulation (Borbély, 1982). We have also shown here that slow-wave oscillations during NREM sleep influence the timing of higherfrequency activity within the spindle frequency range. This is consistent with our previous findings (Perentos et al., 2015)

and with findings in humans (Mölle et al., 2002). The observation of more sleep occurring in the unaffected animals during the deprivation interval (Fig. 4E), although not significant, may reflect a better ability of unaffected sheep to avoid the human handler by seeking protection within the flock.

Although we had previously described deficits in CLN5 ${ }^{-1-}$ sheep SWA (Perentos et al., 2015), the neural origin of these deficits remained unclear. They may have been the result of brain atrophy leading to overall reduced EEG amplitude or due to sleep-specific effects. Here, within the framework of sleep homeostasis, we explored this question further. The synaptic homeostasis hypothesis posits that one function of sleep is to "renormalize" synaptic strengths that had been potentiated through daytime activity (Tononi and Cirelli, 2003). Synaptic downscaling is thought to take place during SWA and the associated prolonged hyperpolarization states. CLN5 ${ }^{-/-}$sheep suffer from blindness and motor abnormalities. We and others (Jolly et al., 2002; Frugier et al., 2008) have observed that, as their disease progresses, $\mathrm{CLN} 5^{-1-}$ sheep have reduced daytime mobility because of these symptoms. One possibility is that the reduced daytime activity may lead to reduced synaptic upscaling, thereby exerting less pressure on the sleep homeostat and in turn leading to reduced SWA. Another possibility that we considered was that the reduced SWA was a direct result of neuronal degeneration or dysfunction in the form of abnormal recruitment of cortical and thalamocortical neurons into synchronous oscillations. Given that the underlying generators of SWA include cortical and thalamocortical oscillators (Crunelli and Hughes, 2010), the latter suggestion would be consistent with the cortical atrophy and thalamic abnormalities observed in both humans (Holmberg et al., 2000) and some animal models of NCL (Kielar et al., 2007; Frugier et al., 2008; von Schantz et al., 2009; Amorim et al., 2015; Sawiak et al., 2015). Our findings do not support the possibility that reduced slow-wave amplitudes are a result of reduced sleep pressure or daytime activity. Rather, they are more consistent with abnormalities that are specific to the thalamocortical network in which an increased sleep pressure exists (as was measured 

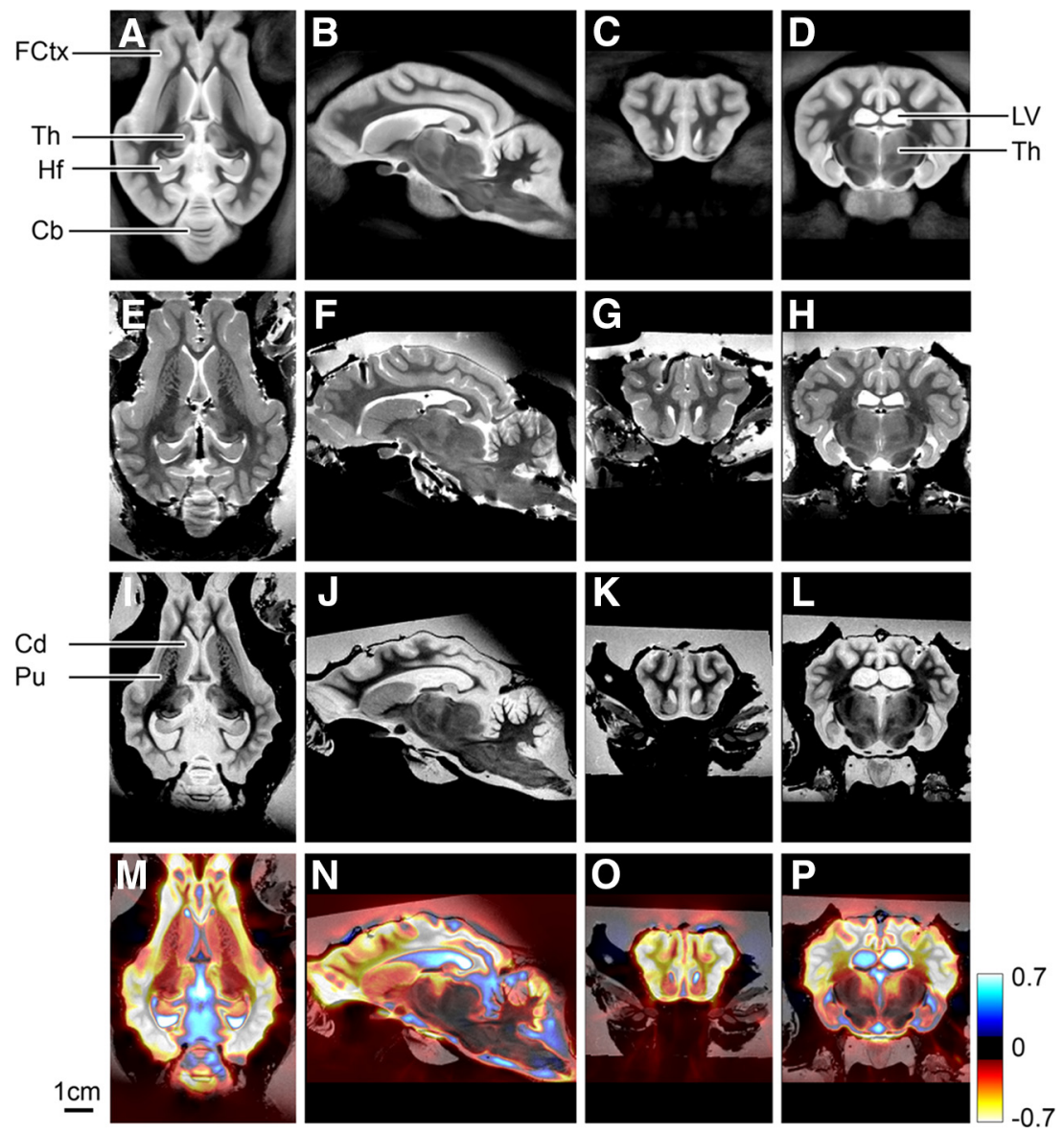

Figure 10. Ex vivo structural MRI brain scans. Results show a template derived from 78 high-resolution ex vivo sheep scans in horizontal $(\boldsymbol{A})$ and sagittal $(\boldsymbol{B})$ sections with coronal sections at the level of the frontal cortex $(\boldsymbol{C})$ and thalamus $(\boldsymbol{D})$. Corresponding sections are shown for a typical heterozygous $\mathrm{CLN} 5^{+/-}$sheep $(\boldsymbol{E}-\boldsymbol{H})$ and a typical affected CLN5 ${ }^{-/-}$sheep $(\boldsymbol{I}-\boldsymbol{L})$, both of which had EEG implants. A map of local volume differences (log Jacobian determinants) is shown for the affected sheep ( $\boldsymbol{M}-\boldsymbol{P})$. The color scale shows decreased relative volume in red colors and increased relative volume in blue colors, such that the full scale shown represents a factor of two in each direction. FCtx, Frontal cortex; Th, thalamus; Hf, hippocampal formation; Cb, cerebellum; LV, lateral ventricles; $\mathrm{Cd}$, caudate; Pu, putamen.

by NREM bout length and amount increases), but the thalamocortical network is unable to respond correctly to this added demand. This interpretation is also supported by the finding that there was no early/late delineation in slow-wave sleep amplitude in CLN $5^{-1-}$ sheep as is seen in unaffected sheep. Our findings are therefore consistent with the possibility of neuronal dysfunction and/or degeneration within the thalamocortical network. We suggest that the need to sleep is likely to persist in Batten disease patients despite the fact that they may experience difficulties in achieving it.

The mechanisms that give rise to the impaired SWA rebound remain unclear. However, the divergent responses within NREM sleep (increased NREM amount/bout duration but absent SWA rebound) may provide clues as to whether these two responses are regulated differentially in Batten disease. For example, the correlation between SWA and the level of extracellular neuroinflammatory factors such as interleukin 1 (IL1) is a well documented phenomenon (Krueger et al., 2008). Importantly, during sleep, the degree of reduction of IL1 correlates with the amplitude of the slow-wave oscillation (Krueger et al., 2008). Of particular relevance is that elevated levels of neuroinflammatory factors are a feature of the NCLs (Lim et al., 2007, Palmer et al., 2013). Therefore, one could speculate that an increase in IL1 or other neuroinflammatory factors may contribute to abnormal signaling of local sleep need and abnormal SWA rebound while at the same time leaving global state switching and sleep drive intact.

Slow-wave events detected from the baseline day recordings revealed lower amplitudes across all four types of slow waves in CLN5 ${ }^{-1-}$ sheep. This difference, however, did not appear to be as pronounced as it was in our previous study, at least in regard to negative-going slow waves that were assessed there (Perentos et al., 2015). Because the sheep in our present study were $\sim 10$ months old and the sheep in our previous study were 14 months old, this may reflect a progressive EEG phenotype. It is also possible that the lower amplitude of positive-going slow waves reflects differential degeneration at the recording sites. For example, the blindness that is later associated with the disease may follow from selective degeneration in cortical visual areas that in turn could lead to reduced slow-wave activity near the reference electrode. However, this cannot be determined using the current data and would require locally referenced recordings (as used for example by Vyazovskiy et al., 2007). Although, in our earlier study, we found decreased NREM and REM amounts in the CLN5 ${ }^{-1-}$ sheep, this effect was not present here. This may be because comparisons were made with a normal group of sheep of the Welsh Mountain breed or (more likely) because the sheep that we used here were younger than those used in our earlier study (10 vs 14 months) and the disease in the younger sheep was less advanced (Perentos et al., 2015). The abnormal timing between sleep spindles and slow waves was similar to results obtained in our previous study (Perentos et al., 2015). The loss of interneuron populations observed in other species models of CLN5 (Kopra et al., 2004; von Schantz et al., 2009) could lead to disrupted thalamocortical networks that are essential for the generation of spindle and slow-wave oscillations (Crunelli and Hughes, 2010).

Because the sheep used in this study were part of a longitudinal study, we were unable to obtain postmortem tissue at the time of the sleep deprivation experiment. Therefore, further investigations are needed to assert the underlying neuropathological correlates of these EEG observations. To the best of our knowledge, there are no studies published showing neuropathology of this sheep line at the age of 10 months, although investigations are currently under way (Palmer et al., 2015b). The earliest pathological changes reported so far in the brain were evident from 19 months on (Amorim et al., 2015) and, by 23 months, there is extensive cortical atrophy. At a behavioral level, abnormalities have been reported as early as 1 year of age, with apparent blindness, low head carriage, and a tendency to walk in circles (Frugier et al., 2008). The sheep that we used in our study had neither gait abnormalities nor clinical signs of blindness, although they did eventually go blind. The discrepancies in the behavioral descrip- 
tions are likely to stem from the housing conditions. These sheep were housed in a barn and were very well habituated to humans. Therefore, they might not show flocking behavior abnormalities that would expose the behavioral changes described by Frugier et al. (2008). It would be interesting to study the flock behaviors of the CLN5 ${ }^{-1-}$ sheep directly. It has been shown that, in Huntington's disease transgenic sheep, flock behavioral deficits appear many years before either brain pathology or neurological signs (Morton et al., 2014). Therefore, despite the lack of symptoms, the possibility of functional neuropathological changes in $\mathrm{CLN}^{-1-}$ sheep at the age of 10 months cannot be excluded, particularly given the reported similarity between the progressive neuropathology in CLN5 and CLN6 sheep, with the latter showing neuropathology at early stages (Palmer et al., 2015b).

Because the deficits that we described in the sheep have not been reported in Batten disease patients, the clinical relevance of our work remains unclear. Nevertheless, whereas the described deficits appear modest, even mild sleep deprivation can have wide-ranging detrimental effects in normal subjects on autonomic and endocrine systems (Meerlo et al., 2008), as well as neurological function and cognition (McCoy and Strecker, 2011). Therefore, there is a strong likelihood that sleep abnormalities in Batten disease patients will also be deleterious. Given the neuroprotective role of sleep (Xie et al., 2013), direct sleep induction may be an interesting therapeutic approach to treating sleep abnormalities in early-stage neurodegenerative disease. Noninvasive interventions such as alternating current stimulation (Marshall et al., 2006, Saebipour et al., 2015) or transcranial magnetic stimulation (Massimini et al., 2007) could also be used to stabilize or induce deeper sleep with increased slow-wave activity. Overall, the results presented here provide evidence of homeostatic control of sleep in unaffected sheep and sleep abnormalities in CLN5 ${ }^{-1-}$ sheep, which warrant further investigation in both patients and in this animal model of the disease.

\section{References}

Amorim IS, Mitchell NL, Palmer DN, Sawiak SJ, Mason R, Wishart TM, Gillingwater TH (2015) Molecular neuropathology of the synapse in sheep with CLN5 Batten disease. Brain Behav 5:e00401. CrossRef Medline

Baud MO, Magistretti PJ, Petit JM (2015) Sustained sleep fragmentation induces sleep homeostasis in mice. Sleep 38:567-579. CrossRef Medline

Bersagliere A, Achermann P (2010) Slow oscillations in human non-rapid eye movement sleep electroencephalogram: effects of increased sleep pressure. J Sleep Res 19:228-237. CrossRef Medline

Beuchée A, Hernández AI, Duvareille C, Daniel D, Samson N, Pladys P, Praud JP (2012) Influence of hypoxia and hypercapnia on sleep statedependent heart rate variability behavior in newborn lambs. Sleep 35: 1541-1549. CrossRef Medline

Bokil H, Andrews P, Kulkarni JE, Mehta S, Mitra PP (2010) Chronux: a platform for analyzing neural signals. J Neurosci Methods 192:146-151. CrossRef Medline

Bonjean M, Baker T, Lemieux M, Timofeev I, Sejnowski T, Bazhenov M (2011) Corticothalamic feedback controls sleep spindle duration in vivo. J Neurosci 31:9124-9134. CrossRef Medline

Borbély AA (1982) A two process model of sleep regulation. Hum Neurobiol 1:195-204. Medline

Borbély AA, Baumann F, Brandeis D, Strauch I, Lehmann D (1981) Sleep deprivation: effect on sleep stages and EEG power density in man. Electroencephalogr Clin Neurophysiol 51:483-495. CrossRef Medline

Brisbare-Roch C, Dingemanse J, Koberstein R, Hoever P, Aissaoui H, Flores S, Mueller C, Nayler O, van Gerven J, de Haas SL, Hess P, Qiu C, Buchmann S, Scherz M, Weller T, Fischli W, Clozel M, Jenck F (2007) Promoting sleep by targeting the orexin system in rats, dogs and humans. Nat Med 13:150-155. Medline

Carskadon MA, Dement WC (1979) Effects of total sleep loss on sleep latency. Percept Mot Skills 48:495-506. CrossRef Medline

Chang R, Liu X, Li S, Li XJ (2015) Transgenic animal models for study of the pathogenesis of Huntington's disease and therapy. Drug Des Devel Ther 9:2179-2188. CrossRef Medline

Contreras D, Steriade M (1995) Cellular basis of EEG slow rhythms: a study of dynamic corticothalamic relationships. J Neurosci 15:604-622. Medline

Crunelli V, Hughes SW (2010) The slow $(<1 \mathrm{~Hz})$ rhythm of non-REM sleep: a dialogue between three cardinal oscillators. Nat Neurosci 13: 9-17. CrossRef Medline

Davis CJ, Clinton JM, Jewett KA, Zielinski MR, Krueger JM (2011) Delta wave power: an independent sleep phenotype or epiphenomenon? J Clin Sleep Med 7:S16-S18. CrossRef Medline

Frugier T, Mitchell NL, Tammen I, Houweling PJ, Arthur DG, Kay GW, van Diggelen OP, Jolly RD, Palmer DN (2008) A new large animal model of CLN5 neuronal ceroid lipofuscinosis in Borderdale sheep is caused by a nucleotide substitution at a consensus splice site $(\mathrm{c} .571+1 \mathrm{G}>\mathrm{A})$ leading to excision of exon 3. Neurobiol Dis 29:306-315. CrossRef Medline

Hajnik T, Tóth A, Détári L (2013) Characteristic changes in the slow cortical waves after a $6 \mathrm{~h}$ sleep deprivation in rat. Brain Res 1501:1-11. CrossRef Medline

Holmberg V, Lauronen L, Autti T, Santavuori P, Savukoski M, Uvebrant P, Hofman I, Peltonen L, Järvelä I (2000) Phenotype-genotype correlation in eight patients with Finnish variant late infantile NCL (CLN5). Neurology 55:579-581. CrossRef Medline

Huber R, Hill SL, Holladay C, Biesiadecki M, Tononi G, Cirelli C (2004) Sleep homeostasis in Drosophila melanogaster. Sleep 27:628-639. Medline

Hughes SM, Hope KM, Xu JB, Mitchell NL, Palmer DN (2014) Inhibition of storage pathology in prenatal CLN5-deficient sheep neural cultures by lentiviral gene therapy. Neurobiol Dis 62:543-550. CrossRef Medline

Jolly RD, Arthur DG, Kay GW, Palmer DN (2002) Neuronal ceroidlipofuscinosis in Borderdale sheep. N Z Vet J 50:199-202. CrossRef Medline

Kielar C, Maddox L, Bible E, Pontikis CC, Macauley SL, Griffey MA, Wong M, Sands MS, Cooper JD (2007) Successive neuron loss in the thalamus and cortex in a mouse model of infantile neuronal ceroid lipofuscinosis. Neurobiol Dis 25:150-162. CrossRef Medline

Kirveskari E, Partinen M, Salmi T, Sainio K, Telakivi T, Hämäläinen $M$, Larsen A, Santavuori P (2000) Sleep alterations in juvenile neuronal ceroid-lipofuscinosis. Pediatr Neurol 22:347-354. CrossRef Medline

Kopra O, Vesa J, von Schantz C, Manninen T, Minye H, Fabritius AL, Rapola J, van Diggelen OP, Saarela J, Jalanko A, Peltonen L (2004) A mouse model for Finnish variant late infantile neuronal ceroid lipofuscinosis, CLN5, reveals neuropathology associated with early aging. Hum Mol Genet 13:2893-2906. CrossRef Medline

Krueger JM, Rector DM, Roy S, Van Dongen HP, Belenky G, Panksepp J (2008) Sleep as a fundamental property of neuronal assemblies. Nat Rev Neurosci 9:910-919. CrossRef Medline

Lim MJ, Alexander N, Benedict JW, Chattopadhyay S, Shemilt SJ, Guérin CJ, Cooper JD, Pearce DA (2007) IgG entry and deposition are components of the neuroimmune response in Batten disease. Neurobiol Dis 25: 239-251. CrossRef Medline

Malcolm C, Hain R, Gibson F, Adams S, Anderson G, Forbat L (2012) Challenging symptoms in children with rare life-limiting conditions: findings from a prospective diary and interview study with families. Acta Paediatr 101:985-992. CrossRef Medline

Marshall L, Helgadóttir H, Mölle M, Born J (2006) Boosting slow oscillations during sleep potentiates memory. Nature 444:610-613. CrossRef Medline

Massimini M, Ferrarelli F, Esser SK, Riedner BA, Huber R, Murphy M, Peterson MJ, Tononi G (2007) Triggering sleep slow waves by transcranial magnetic stimulation. Proc Natl Acad Sci U S A 104:84968501. CrossRef Medline

McCoy JG, Strecker RE (2011) The cognitive cost of sleep lost. Neurobiol Learn Mem 96:564-582. CrossRef Medline

Meerlo P, Sgoifo A, Suchecki D (2008) Restricted and disrupted sleep: effects on autonomic function, neuroendocrine stress systems and stress responsivity. Sleep Med Rev 12:197-210. CrossRef Medline

Mole SE, Cotman SL (2015) Genetics of the neuronal ceroid lipofuscinoses (Batten disease). Biochim Biophys Acta 1852:2237-2241. CrossRef Medline

Mole SE, Williams RE, Goebels HH (2011) The neuronal ceroid lipofuscinoses (Batten disease). New York: OUP. 
Mölle M, Marshall L, Gais S, Born J (2002) Grouping of spindle activity during slow oscillations in human non-rapid eye movement sleep. J Neurosci 22:10941-10947. Medline

Morton AJ, Howland DS (2013) Large genetic animal models of Huntington's disease. J Huntingtons Dis 2:3-19. CrossRef Medline

Morton AJ, Rudiger SR, Wood NI, Sawiak SJ, Brown GC, McLaughlan CJ, Kuchel TR, Snell RG, Faull RL, Bawden CS (2014) Early and progressive circadian abnormalities in Huntington's disease sheep are unmasked by social environment. Hum Mol Genet 23:3375-3383. CrossRef Medline

Musiek ES, Xiong DD, Holtzman DM (2015) Sleep, circadian rhythms, and the pathogenesis of Alzheimer Disease. Exp Mol Med 47:e148. CrossRef Medline

Palmer DN (2015a) The relevance of the storage of subunit c of ATP synthase in different forms and models of Batten disease (NCLs). Biochim Biophys Acta 1852:2287-2291. CrossRef Medline

Palmer DN, Barry LA, Tyynelä J, Cooper JD (2013) NCL disease mechanisms. Biochim Biophys Acta 1832:1882-1893. CrossRef Medline

Palmer DN, Neverman NJ, Chen JZ, Chang CT, Houweling PJ, Barry LA, Tammen I, Hughes SM, Mitchell NL (2015b) Recent studies of ovine neuronal ceroid lipofuscinoses from BARN, the Batten Animal Research Network. Biochim Biophys Acta 1852:2279-2286. CrossRef Medline

Perentos N, Martins AQ, Watson TC, Bartsch U, Mitchell NL, Palmer DN, Jones MW, Morton AJ (2015) Translational neurophysiology in sheep: measuring sleep and neurological dysfunction in CLN5 Batten disease affected sheep. Brain 138:862-874. CrossRef Medline

Piano C, Losurdo A, Della Marca G, Solito M, Calandra-Buonaura G, Provini F, Bentivoglio AR, Cortelli P (2015) Polysomnographic findings and clinical correlates in Huntington disease: a cross-sectional cohort study. Sleep 38:1489-1495. CrossRef Medline

Radke J, Stenzel W, Goebel HH (2015) Human NCL neuropathology. Biochim Biophys Acta 1852:2262-2266. CrossRef Medline

Saebipour MR, Joghataei MT, Yoonessi A, Sadeghniiat-Haghighi K, Khalighinejad N, Khademi S (2015) Slow oscillating transcranial direct current stimulation during sleep has a sleep-stabilizing effect in chronic insomnia: a pilot study. J Sleep Res 24:518-525. CrossRef Medline

Santavuori P, Linnankivi T, Jaeken J, Vanhanen SL, Telakivi T, Heiskala H (1993) Psychological symptoms and sleep disturbances in neuronal ceroid-lipofuscinoses (NCL). J Inherit Metab Dis 16:245-248. CrossRef Medline

Santavuori P, Lauronen L, Kirveskari E, Aberg L, Sainio K, Autti T (2000) Neuronal ceroid lipofuscinosis in childhood. Neurol Sci 21:S35-S41. CrossRef Medline

Sawiak SJ, Perumal SR, Rudiger SR, Matthews L, Mitchell NL, McLaughlan CJ, Bawden CS, Palmer DN, Kuchel T, Morton AJ (2015) Rapid and progressive regional brain atrophy in CLN6 Batten disease affected sheep measured with longitudinal magnetic resonance imaging. PLoS One 10: e0132331. CrossRef Medline

Tabrizi SJ, Scahill RI, Owen G, Durr A, Leavitt BR, Roos RA, Borowsky B, Landwehrmeyer B, Frost C, Johnson H, Craufurd D, Reilmann R, Stout JC, Langbehn DR; TRACK-HD Investigators (2013) Predictors of phenotypic progression and disease onset in premanifest and early-stage Huntington's disease in the TRACK-HD study: analysis of 36-month observational data. Lancet Neurol 12:637-649. CrossRef Medline

Tobler I, Jaggi K, Arendt J, Ravault JP (1991) Long-term 24-hour restactivity pattern of sheep in stalls and in the field. Experientia 47:744-749. CrossRef Medline

Tononi G, Cirelli C (2003) Sleep and synaptic homeostasis: a hypothesis. Brain Res Bull 62:143-150. CrossRef Medline

Veneselli E, Biancheri R, Perrone MV, Buoni S, Fois A (2000) Neuronal ceroid lipofuscinoses: clinical and EEG findings in a large study of Italian cases. Neurol Sci 21:S75-S81. CrossRef Medline

von Schantz C, Kielar C, Hansen SN, Pontikis CC, Alexander NA, Kopra O, Jalanko A, Cooper JD (2009) Progressive thalamocortical neuron loss in Cln5 deficient mice: Distinct effects in Finnish variant late infantile NCL. Neurobiol Dis 34:308-319. CrossRef Medline

Vyazovskiy VV, Riedner BA, Cirelli C, Tononi G (2007) Sleep homeostasis and cortical synchronization: II. A local field potential study of sleep slow waves in the rat. Sleep 30:1631-1642. Medline

Vyazovskiy VV, Cirelli C, Tononi G (2011) Electrophysiological correlates of sleep homeostasis in freely behaving rats. Prog Brain Res 193:17-38. CrossRef Medline

Xie L, Kang H, Xu Q, Chen MJ, Liao Y, Thiyagarajan M, O’Donnell J, Christensen DJ, Nicholson C, Iliff JJ, Takano T, Deane R, Nedergaard M (2013) Sleep drives metabolite clearance from the adult brain. Science 342:373-377. CrossRef Medline 